\title{
El Partido Socialista argentino, el sindicalismo y la organización de las enfermeras de Buenos Aires en la década de 1930
}

\author{
The Argentine Socialist Party, trade unionism, and the \\ organization of nurses in Buenos Aires in the 1930s
}

Diego Ceruso*

\section{RESUMEN}

El trabajo propone un cruce entre la historia social y la historia

Palabras clave: política, con el objetivo de indagar, desde una dinámica relacional, el proceder del Partido Socialista (PS) argentino en el campo gremial, a través del desenvolvimiento de la Unión de Obreros y Empleados Municipales y en la interpelación y organización de las trabajadoras de la enfermería en los hospitales porteños. Ello lo haremos, principalmente, a través de fuentes gremiales, el periódico El Obrero Municipal y de la publicación orientada por y para mujeres ligada al PS, Vida Femenina, aunque además Partido Socialista, sindicato municipal, enfermeras porteñas, organización sindical de las mujeres. abordaremos diversas fuentes partidarias. Los resultados de la investigación ofrecen un mejor conocimiento de la experiencia gremial socialista en la oferta y el nivel de concreción de la compleja articulación entre lo sindical, lo político y las mujeres trabajadoras, en el contexto de la década del treinta en la ciudad de Buenos Aires.

\section{SUMMARY}

The work proposes a cross between social and political history, to Keywords: Socialist investigate, from a relational dynamic, the actions of the Argentine Socialist Party (PS) in the field of unions, through the develParty, municipal union, Buenos opment of the Union of Workers and Municipal Employees and

* Argentino. Profesor de Enseñanza Media y Superior, Licenciado y Doctor en Historia, Universidad de Buenos Aires, Argentina. Investigador, Consejo Nacional de Investigaciones Científicas y Técnicas, Instituto de Historia Argentina y Americana Dr. Emilio Ravignani, Buenos Aires, Argentina. E-mail: diegoceruso@gmail.com 
El Partido Socialista argentino, el sindicalismo y la organización de las enfermeras de | Ceruso

in the questioning and organization of nursing workers in Buenos Aires hospitals. We will do this, mainly through trade union women's union sources, the newspaper El Obrero Municipal and the publication organization. oriented by and for women linked to the PS, Vida Femenina, although we will also address various party sources. Research results offer a better understanding of the socialist union experience at the consolidation level between unions, politics, and working women in Buenos Aires' 1930s decade. 
Desde fines del siglo XIX, el crecimiento del número de trabajadores se constituyó en uno de los procesos más dinámicos de la vida política, económica, social y cultural argentina. En paralelo, las izquierdas, como campo político, cultural e ideológico, delinearon un espacio heterogéneo en estrecha relación con aquel sujeto. Observar los lazos orgánicos y los vasos comunicantes entre ambos sujetos, creemos, permite atender la compleja y diversa experiencia conjunta sin por ello desatender a sus aspectos específicos. En este caso, nuestra apuesta, que propone un cruce entre la historia social y la historia política, recae en la indagación de la relación entre tres niveles: por un lado, el proceder del Partido Socialista argentino (PS) en el campo gremial; luego, el desenvolvimiento de la Unión de Obreros y Empleados Municipales (UOEM), y, por último, la experiencia sindical de las trabajadoras de enfermería de los hospitales porteños. Algunos interrogantes orientan nuestra pesquisa: ¿qué reivindicaciones específicas tenían estas trabajadoras?, ¿cuál fue el modo en que el sindicato interpeló a este sector en particular dentro de sus filas?, ¿existió una mirada específica del PS respecto del trabajo femenino en los hospitales porteños?, ¿de qué modo se relacionó el PS y la UOEM con estas trabajadoras en ese siempre intrincado vínculo entre el partido y los sindicatos que orientaban los cuadros socialistas?

La pesquisa, entendemos, habilita la posibilidad de un mejor conocimiento de una de las empresas políticas de izquierda de más larga tradición e importancia en Argentina. Nuestra propuesta recae en la exploración de esa experiencia durante la década del treinta en la ciudad de Buenos Aires, entre el partido, el sindicato y ese sector feminizado de la fuerza de trabajo, con la intención de que ello nos permita un mejor conocimiento de la oferta y el nivel de concreción de la articulación entre lo sindical, lo político y la organización gremial de las mujeres. Lo haremos principalmente a través de fuentes gremiales, el periódico El Obrero Municipal, y de la publicación orientada por y para mujeres ligada al PS, Vida Femenina, aunque además abordaremos diversas fuentes partidarias.

Tanto la clase trabajadora como las izquierdas ocuparon un lugar de importancia en la vida política, social y cultural del país durante el periodo analizado. Allí radica una de las razones por las cuales se vuelve relevante revisar el vínculo que ambos sujetos forjaron. Esta 
búsqueda de amalgamiento está basada en la convicción acerca de la dinámica conjunta que, de otro modo, quedaría mutilada en tanto presentaría caminos bifurcados (Camarero, 2007 y Ceruso, 2015, entre otros). En este caso, nuestra intención es el examen del PS en su lazo con uno de los espacios gremiales de mayor importancia en su vasta y compleja trayectoria. Como veremos más adelante en detalle, entre los municipales se encontraba probablemente su figura de mayor envergadura en el campo sindical: Francisco Pérez Leirós.

Estudiar el movimiento obrero como parte de la clase, implica evitar las simplificaciones analíticas para poder dar cuenta de la riqueza del objeto. Con esa intención, procuramos atender

"el desarrollo y el desplazamiento de las contradicciones de clase, las transformaciones sociales y las mutaciones socioprofesionales que se operan en el seno de la clase y del movimiento obrero como consecuencia de las transformaciones estructurales y tecnológicas de la sociedad capitalista, los cambios realizados en el proceso objetivo de enfrentamiento de las fuerzas sociales, sus efectos políticos, ideológicos, sociales y su implicación en los distintos niveles de la lucha obrera, las constantes y las rupturas que de todo esto resultan" (Haupt, 1986: 30).

Esta apuesta conlleva como objetivo abordar a una clase obrera que entendemos heterogénea en términos de género, raza, etnia y sexualidad, y que, a la vez, esa complexión es estructurante y tensionante de las relaciones sociales que despliega. En este plano, esta experiencia entre el PS, el sindicato y la fuerza de trabajo femenina de los hospitales porteños nos conduce a desentrañar el modo de vinculación con uno de los sectores de la reproducción social (Vogel, 2013). El trabajo encarado entendemos que representa un aporte, en tanto el sector de la enfermería no había sido estudiado con relación a su organización y vínculo con la estructura sindical y política. Allí, en el repaso del vínculo entre el PS, la Unión de Obreros y Empleados Municipales y las enfermeras porteñas, entendemos recae la originalidad y contribución del presente estudio. Además, observar esta experiencia entre el partido, el sindicato y la fuerza de trabajo femenina de los hospitales porteños nos condujo a escrutar el modo de vinculación con uno de los sectores de la reproducción social. Así, el rol de las trabajadoras de 
hospitales se vuelve un área central en la reproducción de la fuerza de trabajo.

Para la época que nos ocupa, la práctica de la enfermería se encontraba fuertemente hegemonizada por mujeres. El trabajo en hospitales, junto con otros sectores como escuelas, geriátricos, guarderías, limpieza, forma parte de las áreas que comprenden las tareas de reproducción social asalariada. $Y$ esa pertenencia e incumbencia en la reproducción social las posiciona con ciertas particularidades que conviene advertir:

"la 'trabajadora asalariada de la reproducción social' es una condición obrera cada vez con más peso, que combina dos tipos de elementos diferenciados: a) aquellos propios del "trabajo asalariado": un lugar de trabajo donde se concentran centenas o miles de trabajadores (como los grandes centros educativos o de salud), posibilidad de negociación colectiva y sindicalización, identificación de un patrón a quien presentarle las demandas laborales y contra quien combatir, relaciones con otros sectores de asalariados, etc.; b) aquellos propios de la reproducción social: no sólo por la naturaleza de las tareas sino también por la relación que se establece con los territorios de la reproducción social: hogares, barrios, comunidades, pueblos" (Varela, 2020: 90).

El trabajo se propone como objetivo mostrar las tensiones que surcaron la experiencia socialista y gremial, para luego observarlo en su vínculo con las trabajadoras de la enfermería. Asimismo, expone que, entre diversas cuestiones, ello estuvo tamizado por la persistencia de un discurso que consideraba a la mujer con un rol subsidiario al hombre, una visión maternalista y, en ocasiones, argumentaciones en términos de competencia salarial. Inicialmente, abordaremos la relación entre el socialismo y el sindicalismo, con la intención de ofrecer una contextualización de la problemática y del escenario para, en segunda instancia, desarrollar la experiencia del PS, el sindicato municipal y las enfermeras de Buenos Aires en los años treinta.

\section{El Partido Socialista y el sindicalismo}

El repaso por la experiencia del PS en el universo sindical conserva aún múltiples interrogantes. Como se ha dicho, examinar su vínculo 
con el movimiento gremial ilumina al mismo tiempo una parte importante de la historia del socialismo y de la izquierda en general, por una parte, y de la clase obrera argentina, por otra, en la primera mitad del siglo XX.

El vínculo entre el partido y los sindicatos fue eje de debates entre los socialistas a nivel global desde fines del siglo XIX. Aunque en el congreso internacional de la socialdemocracia de Bruselas, en 1891 y en el de Zúrich, en 1893, la temática fue abordada, fue recién en el realizado en Londres en 1896 en donde se discutió específicamente (Poy, 2016: 22). Allí se aprobó la siguiente resolución:

"la lucha sindical de los trabajadores es indispensable para resistir la tiranía económica del capital, y por lo tanto mejorar su situación actual. Pero esta lucha económica no puede suprimir por completo la explotación capitalista, solo puede suavizarla. La organización de la clase obrera será incompleta e insuficiente mientras no esté organizada políticamente. Lo que sea que obtengan los trabajadores de los patrones en disputas abiertas debe ser confirmado por la ley para poder ser conservado, mientras que los conflictos sindicales pueden en otros casos ser innecesarios debido a medidas legislativas".

La confirmación de la independencia de esferas, aunque establecía la complementación, al mismo tiempo dotaba de cierta supremacía a la actividad política, en tanto ésta se presentaba como la herramienta que otorgaba carácter definitivo y completo a la acción de los trabajadores.

El PS argentino, fundado en 1896, logró establecerse desde sus inicios como una estructura con presencia en la sociedad. Con un gran despliegue territorial de alcance nacional, su implantación en la vida política argentina no demoró en llegar. Además del plano electoral, las numerosas instituciones culturales (centros políticos, bibliotecas, asociaciones deportivas, etcétera), junto a un gran número de publicaciones (libros, periódicos y revistas), lo convirtieron en un actor de importancia en ese plano. En paralelo, había impulsado campañas para

1 Congrès international socialiste des travailleurs et des chambres syndicales ouvrières, Londres 26 juillet-2 août 1896 [Reprint], Minkoff, Ginebra, 1980, p. 384. Citado en Poy, 2016: 22 . 
mejorar las condiciones de vida de la población, desarrollar el cooperativismo y extender la legislación obrera (Tortti, 1989; Aricó, 1999). Sus indudables logros en la esfera política, parlamentaria y cultural fueron acompañados por una menos firme constitución como fuerza partidaria en el movimiento obrero. Su experiencia con el movimiento sindical no estuvo exenta de fricciones, discusiones internas y rupturas partidarias. $^{2}$

Casi desde su creación, el PS planteaba tres áreas de acción de cara a los trabajadores. El gremialismo, el cooperativismo y la acción política propiamente dicha, se erigían como campos relacionados, pero con sus especificidades:

“de las tres formas de organización, se sostenía la supremacía de la acción política -entendida como actividad parlamentaria-, pues mediante ella la clase obrera eludiría el 'exclusivismo corporativo' y se propondría 'la conquista del poder público por medio del sufragio universal y de las libres instituciones democráticas, para transformar la organización capitalista de la actual sociedad en organización colectivista de la misma'. En cuanto a los sindicatos obreros, se los consideraba autónomos en su terreno y fin específicos: el del mejoramiento de las condiciones de vida y trabajo de sus miembros. Sin embargo, ellos necesitarían de la organización política para poder completar su obra, pues sin la sanción de una legislación favorable las conquistas obreras tendrían carácter efímero" (Tortti, s/f: 2). ${ }^{3}$

Desde sus orígenes, aunque con fuertes debates, la voluntad oficial, en gran medida impulsada por su máxima figura y referente Juan B. Justo, fue la de escindir el plano político del gremial (Belkin, 2018; Martínez Mazzola, 2011; Poy, 2014). Esta autonomía, materializada en la "Declaración de Avellaneda" del XIV Congreso Ordinario en 1918, era una expresión de una concepción más amplia sobre la necesidad de

2 La discusión sobre el vínculo con el movimiento obrero le había generado al PS costosas disputas internas. Por ejemplo, a fines del siglo XIX la tensión con los "colectivistas", en 1906 con la ruptura sindicalista, en la segunda década del siglo XX con el Comité de Propaganda Gremial y la más tardía formación del Partido Socialista Internacional.

3 Los entrecomillados son citas que Tortti toma de López (1935) y Dickmann (1946). Recordemos brevemente la clásica referencia de Jacinto Oddone: "el movimiento socialista, decíamos, marcha sobre dos piernas: la lucha económica -gremial, cooperativa- y la lucha política" (Oddone, 1983: 287). 
construir una opción partidaria reformista, que buscara la integración al sistema social y político y que subordinara la conflictividad entre capital y trabajo a elementos más globales, entre otras características. Pero esta desarticulación de esferas, que si se quiere ir más allá fue incluso una disociación con algunos aspectos centrales de la lucha y la organización obrera, estuvo sujeta a fuertes tensiones internas y cuestionamientos (Camarero, 2015).

Durante la primera mitad de la década de 1930, un sector compuesto principalmente por cuadros gremiales y liderados por Pérez Leirós pareció tener una política más activa y mayor presencia en las publicaciones partidarias. Así, a partir de 1930, pero con marcado énfasis desde 1932, aquellos que propiciaban una relación más directa y fluida entre el partido y los sindicatos fueron ganando peso en la Comisión Socialista de Información Gremial (CSIG), representación en los Congresos y visibilidad en los medios del PS. ${ }^{4}$ Prueba de ello son las composiciones de la Comisión Gremial, en las que la mayoría de sus integrantes se enrolaban en las posiciones encabezadas por Pérez Leirós, líder de los municipales; la presencia regular de intervenciones críticas a la dirección partidaria en relación al desempeño sindical del PS en la prensa y otros órganos de difusión editorial y, quizá el punto más sintomático, el Despacho Gremial del Congreso de Santa Fe en 1934, que contrariaba la postura tradicional de la "Declaración de Avellaneda" y marcaba una delimitación, con cierta prudencia, en el interior del PS con quienes buscaban mantener la independencia de acción entre la esfera política y la sindical (Ceruso, 2017a; Matsushita, 1986; Tortti, 1989, La Vanguardia, 28-V-1934).

A nuestro entender, esto no implicó un cambio de estrategia del PS sino más bien una modulación de la política oficial. Había, al menos, dos fuertes motivaciones que influyeron en esta modificación táctica. La primera, la presencia de los sindicalistas en la conducción de la Confederación General del Trabajo (CGT), que llevaron al extremo su perfil negociador, pragmático, moderado y conciliador, junto a su discurso neutralista, de rechazo a las influencias políticas (Del Campo,

4 Por ejemplo: Anuario Socialista, Buenos Aires, 1934; Revista Socialista, Buenos Aires, I-1933 y Revista Socialista, II-1933; CSIG, Organización y acción gremial de los trabajadores, Buenos Aires, 1933. 
2005; García, 2017). Esto permitió polarizar al PS y contraponer a ello una política más activa en el movimiento sindical, que se expresó no solo en la lucha contra el fascismo sino además en las críticas al cuerpo de ideas tradicional del sindicalismo (CSIG, XI-1934). La segunda de las causas pareció ser de índole interna. La existencia de una relanzada "izquierda" partidaria que fustigaba a la dirección y planteaba una serie de modificaciones programáticas, estratégicas y estructurales que redefinirían el rumbo, más bien el sentido, del PS (Herrera, 2019). No resulta inverosímil que la conducción partidaria haya propiciado una mayor presencia del grupo encabezado por Pérez Leirós, para mostrarse permeable a las críticas referidas al rol en el ámbito gremial y así atemperar, parcialmente, la influencia del sector izquierdista encabezado por Benito Marianetti en la base del PS. Un tercer factor, tenue aún, pero que pudo influir en esta variación política, fue la intención de la dirección del partido de no desatender la creciente incidencia comunista entre los trabajadores industriales principalmente.

Pero este escenario se fue difuminando a partir de 1935, dado que el sector "izquierdista" fue paulatinamente diezmado, aunque persistió entre el cónclave de Santa Fe y el Congreso Extraordinario para la reforma de estatutos de 1935, y el núcleo dirigente sindicalista fue depuesto de la CGT en diciembre de ese mismo año. Eso permitió a la dirección del PS retomar la senda de la escisión del plano político del gremial, expresada en 1918 y presente de hecho con anterioridad. Luego de 1935, las expresiones disonantes de la estrategia oficial quedarían relegadas y la política enarbolada por los socialistas en la CGT replicó una tendencial pero cada vez más marcada autonomía de las corrientes políticas. Aún más, la CSIG, elemento más dinámico de aquellas críticas y bastión de quienes profesaban entre 1930 y 1935 una modificación en la vinculación entre el partido y los sindicatos, no se mostró vital durante la segunda mitad de los años treinta y quedó reducida a una expresión nominal, situación que había sido habilitada por la reforma de estatutos de 1935, en la que el Comité Ejecutivo (CE) se reservaba el control de la composición de la Comisión (Acción Gremial, IV-1935). Así, no es de extrañar que las posturas de la CSIG y de la dirección del PS confluyeran en la práctica. El debilitamiento gradual de la "izquierda" del Partido y el desplazamiento de los sindicalistas de la CGT hacían ya innecesario un discurso contrario a la prescindencia. Además, la independencia de esferas 
servía ahora a los intereses de denunciar el proceder de los comunistas y su política de "tutelaje", se acusaba, en los cada vez más pujantes sindicatos industriales, tras la adopción de la estrategia del "frente popular" y su incorporación a la CGT. Así, la prescindencia socialista funcionaba también como un dique de contención frente al avance gremial del PC y la presión que éste ejercía (Ceruso, 2017b).

Tras la obtención de la conducción de la CGT, el PS pareció abandonar los debates de la primera mitad de la década del treinta. El partido, principalmente su dirección, estructuró un nuevo "retorno a Justo" y a su estrategia de independencia del plano político y el gremial. Esta división de esferas tuvo su ejemplificación más nítida en la virtual desaparición de la CSIG como un organismo con posturas propias y críticas a la conducción partidaria, como había ocurrido en los años previos. Como dijimos, dicha Comisión, durante 1936 y 1937, no ejerció un rol de relevancia en el plano gremial y, al igual que las voces disidentes dentro del PS, no tuvo una presencia en las publicaciones partidarias que, más bien, se preocuparon por reponer la idea de la preeminencia de lo político, denunciar el embanderamiento sindical y destacar la centralidad de la prescindencia. ${ }^{5}$ Este panorama se complementó con las tenues expresiones críticas de Pérez Leirós durante el periodo, referente del grupo que propiciaba estrechar lazos entre el Partido y el movimiento obrero, y la pérdida de centralidad de la temática gremial en los congresos partidarios de esos años, ambos elementos que contrastan con el momento inmediatamente anterior. Al promover la prescindencia, el PS pudo confluir con el sector liderado por el socialista ferroviario José Domenech en la CGT, ${ }^{6}$ aunque ello no implicó las desavenencias en otros aspectos entre el PS y la CGT. Este desinterés del PS por estructurar una estrategia firme para influir en el movimiento obrero, habilitó a la CGT - y a su conducción- a construir una senda autónoma y anclada en reclamos económicos y meramente sindicales. Hacia adelante, esta tendencial conducta sería cuestionada, dentro de la central obrera, por comunistas y socialistas que propiciaban acercar su dinámica a los partidos políticos.

$5 \quad$ Jessica Blanco (2018) introdujo en su investigación matices de relevancia respecto del comportamiento de la dirección nacional en su vínculo con el sindicalismo.

6 Entre otros: CGT, 20-VIII-1937; Confederación General del Trabajo, Memoria y balance, 1937-1939, 1939. 
En los años siguientes, dos elementos parecieron confirmarse. Uno, la reafirmación de la independencia del ámbito político del gremial por parte del PS y, segundo, la materialización del PC como un actor de fuste en el movimiento obrero, fundamentalmente industrial. En los años finales de la década del treinta, el contexto de mayor enfrentamiento entre los líderes de la CGT y los dirigentes comunistas y socialistas más ligados al Partido convirtió a la central obrera en una caja de resonancia, y a la experiencia sindical de estos años en la arena en la que se saldaron múltiples debates en los cuales el PS intervino y delineó su estrategia, o la ausencia de ella, de cara al movimiento obrero (Camarero, 2015; Ceruso, 2017b; Del Campo, 2005; Matsushita, 1986; Herrera, 2019).

Así, se desarrolló un ejercicio prescindente del PS y la CGT, junto a la oposición a ello encarnada por la cada vez más relevante presencia comunista en el movimiento obrero industrial y en la central obrera. Como se ha señalado, el PS construyó un cuerpo de ideas específico en torno al gremialismo:

“de manera más general, se pensaba la relación Partido/movimiento obrero en términos de educación, entendida en sentido amplio, lo que incluía la importancia de un trabajo constructivo, vía la legislación. La interacción se daba, en definitiva, por fuera del movimiento obrero, ante todo en el ámbito parlamentario, donde los legisladores socialistas actuaban como poleas de transmisión de los reclamos gremiales, que pasaban a su vez por ese tamiz reformista" (Herrera, 2016: 42).

La experiencia sindical del socialismo contenía más que una mera desarticulación de esferas entre lo político y lo gremial. Implicaba, además, una disociación con algunos aspectos centrales de la lucha y la organización obrera. La concepción evolutiva, los reparos a la autonomía obrera y el rechazo a la violencia argumentaban una postura contraria a las huelgas (La Vanguardia, 20-IV-1942). La prescindencia era una expresión de una concepción más amplia sobre la necesidad de construir una opción partidaria reformista:

"el problema en el socialismo argentino era más profundo que una mera desarticulación entre lo sindical y lo político. Lo que existía era una concepción que subordinaba las contiendas entre el tra- 
bajo y el capital a una faena de reforma e integración social, idealizando la lucha de clases como una suerte de disputa retórica de proyectos en el terreno neutro de un ágora. El PS desconfiaba de las prácticas de autodeterminación de las masas y de las capacidades creadoras de la lucha de clases, la que debía canalizarse para evitar sus desbordes y el despliegue de su potencialidad barbárica" (Camarero, 2011: 60).

Para el PS, la acción política, como superadora de la incierta práctica huelguística y en tanto instancia en la que se expresaban los intereses de la clase obrera en su conjunto, debía orientar el proceder. En consecuencia, y en los hechos, el socialismo se mantuvo, y reforzó, su política prescindente, de desarticulación entre lo político y lo gremial y de rechazo a la injerencia en las refriegas entre capital y trabajo (Ceruso, 2019a y 2019b). Tras este breve repaso por la historia del vínculo entre el PS y el sindicalismo, abordaremos a continuación el desenvolvimiento del socialismo y de la Unión de Obreros y Empleados Municipales con la organización gremial de las enfermeras de la ciudad de Buenos Aires durante el transcurso de los años treinta.

\section{La Unión de Obreros y Empleados Municipales, las enfermeras porteñas y la organización sindical de las mujeres}

La UOEM había sido fundada en 1916, producto del trabajo directo del PS y de su Comité de Propaganda Gremial. A partir de allí, y durante la década de 1920, ganó de forma paulatina representación con los trabajadores y frente a las autoridades municipales. Tempranamente entre sus filas surgió la figura de Francisco Pérez Leirós quien, tras tres años iniciales de Domingo Mastrolorenzo, no abandonó el cargo de secretario general hasta la intervención del sindicato a mediados de $1944 .{ }^{7}$ La influencia del PS en el sindicato era notoria, no solo por la presencia de Pérez Leirós, quien probablemente fue la figura más importante del partido en el campo gremial, sino además porque la ciudad de Buenos Aires constituyó una base territorial de relevancia en la disposición e implantación del PS. Además, existían otras tres estructuras sindicales

$7 \quad$ Además, Pérez Leirós fue electo diputado nacional por el socialismo en 1924 y luego renovó su banca en cuatro ocasiones. 
de menor relevancia que la UOEM: la primera, la Asociación de Trabajadores de la Comuna, creada en 1927, en la que revistaban figuras como Pedro Milesi y Sebastián Ferrer; la Federación de Obreros y Empleados Municipales, fundada en 1936 y bastión de José Fernando Penelón y su partido Concentración Obrera; por último, la Asociación Porteña de Trabajadores (Di Tella, 2003: 397). El sindicato contaba con una Caja Municipal de Previsión Social que estaba organizada por el municipio, pero tenía representantes obreros, un campo de deportes edificado en un terreno cedido por la comuna y construido con un subsidio municipal.

Más allá que Pérez Leirós representara dentro del PS una posición que buscaba el trabajo más estrecho entre el partido y los sindicatos orientados por cuadros socialistas, dentro de la UOEM eso no pareció plasmarse con nitidez. Por caso, en su disputa con la Asociación de Trabajadores de la Comuna, y tras las acusaciones de hacer política en el sindicato, el periódico sindical aclaraba con inconfundible glosario socialista: " $\mathrm{iNunca}$ se ha hecho nada de eso! Ni cosa alguna tendiente a embanderar la organización" (El Obrero Municipal, 1-VIII-1930). Incluso, no faltaban notas del propio Pérez Leirós denunciando el embanderamiento de las organizaciones sindicales que propiciaban los modelos propuestos por los anarquistas y los comunistas (El Obrero Municipal, 16-III-1934). Así, parece excesivamente lineal aquello que la UOEM "era uno de los pocos gremios que actuaba siempre de acuerdo con el criterio socialista" (Matsushita, 1986: 205). En la práctica, Pérez Leirós pareció sostener el concepto de "prescindencia" con mayor ahínco hacia dentro de su propio gremio que hacia afuera. Aún más claro era el secretario general de la UOEM frente al Congreso normalizador de la CGT:

"el Congreso tiene que abordar el estudio y sanción de su carta orgánica y posiblemente ha de debatirse en el mismo el viejo problema de la 'prescindencia sindical' asunto que por muy trillado no podrá tomar caracteres extraños a los ya conocidos, pero convendrá remarcar en ese Congreso que el bien de la organización sindical de los trabajadores no debe estar vinculada a partidos políticos para difundir sus ideas; programas, plataformas, apoyar candidaturas o poner a su alcance los recursos de los sindicatos, no puede ser indiferente a ningún problema de carácter político que tenga rela- 
ción con la libertad de prensa, de reunión, de asociación, etcétera, y mucho menos todas aquellas cuestiones de carácter económico que puedan incidir en el alza o depresión de los salarios, como asimismo en todos aquellos aspectos que tengan relación con la vivienda, la instrucción pública y consumos populares" (El Obrero Municipal, 1-IV-1936).

De manera contraria, aunque no necesariamente contradictoria pues se trataba de ámbitos e instancias diferentes, los contrapuntos entre la dirección partidaria del PS y el sector encabezado por Pérez Leirós fueron examinados en detalle, principalmente en los Congresos del PS y en la dinámica interna de la CGT (Ceruso, 2019a y 2019b).

La Municipalidad de la ciudad de Buenos Aires empleaba alrededor de 26.000 trabajadores en la primera mitad de la década de 1920, entre quienes se encontraban barrenderos, mantenimiento general, personal de talleres, hospitales, etcétera. El salario municipal estaba por encima de la media, pues percibían entre 165 y 200 pesos mensuales, cuando el sueldo promedio de un obrero de industria oscilaba en los 109 pesos (Horowitz, 2004, 70-71). El personal femenino rondaba el $20 \%$ del total empleado y revistaban principalmente como mucamas, empleadas administrativas y enfermeras. La enfermería en los hospitales porteños era una labor feminizada desde los inicios del siglo XX pues, con anterioridad, la presencia de hombres al cuidado de enfermos no era inusual (Rubinzal et al., 2019; Wainerman y Binstock, 1993). La modificación sustancial fue consecuencia de una ordenanza de 1912:

"el cambio giró alrededor de cuatro cuestiones principales: limitar la inscripción solo a alumnas mujeres, limitarla solo a externas caducando así la ordenanza de 1905 relativa a la obligatoriedad de los hospitales de hacer capacitar a su personal a través de la Escuela, reformar el plan y la duración de los estudios, y establecer un periodo de un año de servicio obligatorio en cualquier dependencia de la Asistencia Pública, requisito sin el cual no se otorgaba el diploma" (Wainerman y Binstock, 1992: 281).

El argumento para dicha resolución resultaba por demás elocuente: "la mujer es más apta que el hombre a esta clase de estudios, para esta tarea de abnegación sincera, que requiere un trato suave y labor 
paciente, algunos conocimientos generales, nociones de higiene, economía doméstica y cierta cultura más propia de la mujer y no del hombre de esa clase social". ${ }^{8}$ Resulta evidente la asociación de la mujer con las tareas que se consideraban una extensión de las labores domésticas y que, a su vez, eran ligadas a las características del cuidado, delicadeza y cariño.

La feminización de esta fuerza de trabajo de los hospitales se fue consolidando junto a las nociones que emparentaban sus tareas como consecuencias de sus dotes naturales a la asistencia, la caridad, el cuidado y el amor. Junto a estas características, la práctica de la enfermería podía mostrar ciertos elementos estructurantes de la profesión y del campo laboral: la dispersión y disparidad de la formación, la coexistencia de enfermeras con título profesional con aquellas que ejercían el oficio como consecuencia de la experiencia misma, la multiplicidad de tareas que podían realizar y la escasa definición legal que las amparaba al respecto, entre varios factores (Martin, 2014; Valobra y Ramacciotti, 2008 y 2010). ${ }^{9}$ Por ejemplo, para mediados de la década de 1930 un informe técnico daba cuenta que el $76 \%$ de las trabajadoras de hospitales no contaban con título alguno (Martin, 2014: 173). Esta situación, indudablemente, acentuaba la mayor presencia femenina como la consecuencia lógica de ser un ámbito reproductivo de la fuerza de trabajo. Esas dotes para el cuidado y la reproducción de la fuerza de trabajo eran naturalizadas por el sindicato al referirse a las mujeres de hospitales de la siguiente manera: "tú misma trabajas para ayudar a tus padres inválidos, a tu esposo enfermo, a tus hijos huérfanos de padre o a tus numerosos hermanos pequeños" (El Obrero Municipal, 1-V-1930). Así, como se ha señalado, "feminización y profesionalización actuaron como dos fuerzas que se unían y se separaban. Se unían, porque la condición femenina, doméstica y maternal permitió a las mujeres el ingreso a ciertos estudios y trabajos; se separaban, cuando

8 Libro de Resoluciones dictadas por la Dirección de la Asistencia Pública, Copiador N ${ }^{\circ} 98$ de la Escuela Cecilia Grierson, 1912-1918. Citado en Wainerman y Binstock, 1992: 281.

9 Muchos de estos elementos y varios más pueden observarse para diversas regiones y momentos en el dossier "La profesionalización del cuidado sanitario. La enfermería en la historia argentina", coordinado por Karina Inés Ramacciotti para la revista Trabajos y Comunicaciones, número 49, 2019. Disponible en https://www.trabajosycomunicaciones.fahce.unlp.edu.ar/issue/view/436. 
los espacios a los que accedían desestimaban los aprendizajes profesionales al resaltar la naturaleza de la condición femenina" (Biernat y Queirolo, 2018: 2).

La exaltación de estas características femeninas se encontraba estrechamente ligada al discurso sobre la maternidad. Era esa misma identidad maternal la que las dotaba de la capacidad y aptitud para el cuidado del otro (Nari, 2004). Así, resultaba usual y reiterado que el propio sindicato interpelara a las trabajadoras en general $-\mathrm{y}$ a las enfermeras en particular- en esos términos: "madres unas, hermanas otras, y no pocas esposas, todas ellas saben de la dureza que importa ganar el pan con el sudor de la frente, y cuánto cuesta contribuir a que el hogar se mantenga dentro de un marco decoroso y compatible con la dignidad humana" (El Obrero Municipal, 16-IX-1939). ${ }^{10}$ Esta maternalización habilitaba, a su vez, la concepción de complementariedad del trabajo femenino (Nari, 2004). Asimismo, el PS, desde su publicación femenina, no parecía presentar una imagen alejada a la del sindicato: "sobre la mujer recae la responsabilidad de la familia; los hijos se formarán a su calor, si es inteligente y preparada, sabrá ayudar al desenvolvimiento de estos pequeños seres, de manera de no destruir su carácter y poniendo amor, mucho amor, podrá formar hombres mejores para la sociedad de mañana" (Vida Femenina, 15-IX-1935). La maternidad iba asociada a valores naturales, como el amor y la mujer. Así, esta última era presentada como la encargada de la crianza de nuevos hombres y se enarbolaba un determinado modelo de familia a partir del cual se evaluarían las conductas (Nari, 2004; Villalta, 2010). En el mismo sentido, en una suerte de carta de lectores, una trabajadora del gremio escribía al periódico y agradecía al sindicato por la conquista de mejores condiciones de trabajo, y también allí se reforzaban los roles familiares: "mi trabajo ya no fue indispensable para comer y pude atender mejor los quehaceres de mi casa" (El Obrero Municipal, 16-VII-1930).

Desde comienzos de la década del treinta, el sindicato fomentó la agremiación de las mujeres y los llamados en esa dirección eran recurrentes (El Obrero Municipal, 16-VI-1938). En simultáneo, la mujer del

10 También la militante feminista Carolina Muzzilli reproducía la imagen de la obrera ligada a la maternidad. Ver El Obrero Municipal, 16-VII-1933. 
gremio e integrante de la familia obrera podía ser vista desde la UOEM como un impedimento a la organización, a la mejora del funcionamiento sindical o a las prácticas gremiales de los hombres:

"hizo un caluroso llamado a las mujeres para que colaboren con los hombres. Cuando vuestros hermanos, esposos o hijos, os digan que van a la asamblea del sindicato o a cualquier acto obrero, no los detengáis. Allí estarán mucho mejor que en el café, en el almacén $\mathrm{u}$ otro sitio pernicioso. A la asamblea van a discutir la forma de que en vuestro hogar haya abundante alimentación, más abrigo, más alegría para que vuestros pequeños se desarrollen con más vigor en sanas y confortables habitaciones y que no sean arrancados a edad temprana para poblar las fábricas y talleres en detrimento de los salarios de los adultos, con exclusivo beneficio de la clase capitalista" (El Obrero Municipal, 1-IX-1930). ${ }^{11}$

De este modo, ciertamente, la UOEM construía la imagen del varón proveedor, responsable de la alimentación, cuidado y bienestar de la familia obrera. Pero, aún más, en ocasiones la mujer era incluso percibida como un obstáculo para la mejor organización gremial. En palabras del propio Pérez Leirós:

"nuestras compañeras, en base a una educación equivocada, consideran que no son de su incumbencia el tratar estos asuntos, lo que es un tamaño error. Las mujeres, más que nadie, pueden apreciar las dificultades que originan en el hogar los salarios reducidos, todas las ventajas alcanzadas por la Unión Obreros Municipales. Deseamos y esperamos que las mujeres no sean un obstáculo para las actividades gremiales de los hombres, padres, hermanos o esposos" (El Obrero Municipal, 16-X-1930).

Como era usual en el gremialismo, y como ha señalado por ejemplo Dora Barrancos (1990) para el caso del anarquismo, en reiteradas ocasiones la convocatoria y apelación a la mujer tenía como eje evitar el alejamiento del hombre de la militancia gremial. El PS acompañaba esa mirada complementaria del rol de la mujer: "algo más debemos

11 Los llamados a la mujer a agremiarse eran recurrentes y eran convocadas para votar en la elección gremial, allí se reparaba en una serie de cuestiones: "La mujer que trabaja lo hace por necesidad y después de su tarea diaria todavía debe dedicar horas, en muchos casos, a labores domésticas". El Obrero Municipal, 16-VI-1938. 
destacar y es la actividad demostrada por las mujeres, que con gran valentía y decisión, no sólo han apoyado a sus compañeros, sino que los han secundado tomando parte en las manifestaciones públicas, ayudando al sostenimiento de los comedores populares y convirtiéndose en tenaces y convencidas propagandistas para obtener el apoyo de todos los obreros" (Vida Femenina, 15-II-1936). ${ }^{12}$ Ese rol de acompañamiento femenino a la militancia masculina era recurrente y podía convivir con explicaciones acerca de los motivos por los cuales las mujeres gozaban de menores derechos o libertades respecto de los hombres:

"nosotras, compañeras, somos esclavas dos veces o más; por lo menos una más que el hombre. Somos esclavas de todas las cosas que es el hombre y a más de él mismo. Si no gozamos de la libertad relativa que él goza es por nuestra propia culpa. Porque dedicamos demasiado tiempo a arruinarnos la cara con afeites y pinturas con el fin de agradar a los abrebocas de las esquinas para ver si hay alguno que nos substraiga a la tiranía de nuestros familiares sin pensar que la mayoría de las veces caemos en otra mayor" (El Obrero Municipal, 16-XI-1930).

En su publicación femenina, el PS buscaba profundizar las explicaciones sobre esa desigualdad y buscaba relacionar la opresión sufrida por la mujer con las tareas domésticas femeninas y reconocer dichas labores:

"la mujer proletaria soporta todavía las consecuencias que se derivan de su doble condición de productora y ama de casa. No ha terminado para ella la jornada cuando abandona la fábrica, el taller o la oficina. Espéranla todavía las tareas domésticas que le llevan todo el tiempo que le queda disponible. No puede ella conocer el placer del ocio que le quieren asegurar las leyes ni puede ejercitar la igualdad de derechos que nadie se atreve a discutirle. ¿Cómo intervenir regularmente en las actividades políticas, gremiales y cooperativas en las cuales su presencia es tan útil y deseable, cuando a la hora en que aquellas se desarrollan debe cocinar, coser, planchar, limpiar, zurcir y realizar, en fin, esas múltiples tareas propias del ama de casa?" (Vida Femenina, 15-IV-1935).

12 Para el aspecto del sufragio y el PS, puede verse Barrancos, 2005 y Becerra, 2009. 
En simultáneo, el sindicato hacía apelaciones en términos de "hombría", "valentía" y “virilidad", tan propias del universo masculino y reiteradas en el campo sindical: "Necesitamos hombres valientes" ( $E l$ Obrero Municipal, 1-IX-1935 y 16-VI-1936). Y en términos similares se expresaba Vida Femenina de cara a la conmemoración del 1 de mayo: "en la tierra de todas las posibilidades, la Fiesta de los Trabajadores debe ser eso: reafirmación serena y viril de un anhelo de vida mejor, sin prejuicios ni tiranías: con libertad" (Vida Femenina, 15-V-1935).

La UOEM abordó la desigualdad salarial entre hombres y mujeres con demandas históricas como "a igual trabajo igual salario" (El Obrero Municipal, 16-I-1941). Atento a la carga de las tareas domésticas que las mujeres debían realizar, la UOEM, ya iniciada la década del cuarenta, propició y en muchos casos aseguró una serie de conquistas específicas para el sector femenino del gremio. Así, resaltaban las licencias por enfermedad, el externado de los hospitales, la jornada de ocho horas, la jubilación femenina a los veinte años de trabajo y la licencia por maternidad 45 días previos y posteriores al parto, por ejemplo ( $E l$ Obrero Municipal, 16-XI-1942 y Anuario Socialista, 1942). En particular, el sindicato resaltaba la organización y la lucha de las enfermeras porteñas, sin dejar de interpelarlas desde su rol materno, que habían sido vitales para obtener la jubilación femenina a los veinte años de servicio (El Obrero Municipal, 1-X-1939, 1-VII-1940 y 1-IX-1940). Aunque las reivindicaciones por la jubilación femenina anticipada eran acompañadas con una propuesta de mayor aporte: "esta petición no importa desconocer las obligaciones que tiene el personal, para que los propios beneficios de la previsión social no sean desnaturalizados. De ahí que este pedido se funde: 1 . En una mayor contribución a la caja por parte del personal femenino. 2. Mayor contribución del Municipio. 3. Disminución del monto de la jubilación de las mujeres que se jubilen a los 20 años" (El Obrero Municipal, 16-XI-1940).

En el plano de las condiciones de trabajo, era recurrente el pedido de las enfermeras por la aplicación de la ordenanza 8744, que otorgaba mejores condiciones de trabajo en las áreas consideradas insalubres, como los incineradores o desinfección, pero con eje central en las trabajadoras de hospitales (mayormente en los hospitales Muñiz y Tornú, por el trato permanente con enfermedades infecciosas), que llevaría la jornada laboral a las seis horas diarias (El Obrero Municipal, 16- 
IX-1939 y 16-VI-1940). En esa misma coyuntura de inicios de los años cuarenta, el PS hacía una encendida reivindicación sobre la militancia gremial femenina:

"ya hemos señalado la injusticia que con ella se comete en cuanto a salarios. Y este abuso se hace extensivo a todos los aspectos de su vida en la fábrica. Por eso la agremiación la reclama y la acción sindical la coloca en un lugar destacado, brindándole los instrumentos de su mejoramiento individual y colectivo. Sólo mediante el trabajo la mujer podrá construir su independencia económica, base incuestionable de la independencia física y espiritual, y es para lograr la dignidad de su trabajo que aparece en la arena de las luchas gremiales, participando en las asambleas, en las huelgas, en las comisiones paritarias y en todos los organismos directivos de la actividad sindical. Impulsemos y fortalezcamos la militancia gremial de la mujer obrera, dándole la libertad, en el seno del hogar, que necesita para ser una fuerza en la lucha. Los trabajadores varones debemos tomar a nuestro cargo algunas de las tareas que hasta hoy han soportado sobre sus espaldas en forma exclusiva las mujeres, muchas de las cuales deben cumplirlas luego de una jornada de fábrica. Hombro con hombro los dos sexos acelerarán su avance hacia mejores condiciones de vida física y moral, y así han comenzado a practicarlo todos aquellos que comprenden el valor de una armónica colaboración" (Vida Femenina, X y XI-1942). ${ }^{13}$

Asimismo, se exigía al Departamento Nacional del Trabajo que hiciera efectivo el cumplimiento de una serie de derechos laborales, entre los que se encontraba el acatamiento de la norma que habilitaba a las trabajadoras al amamantamiento de sus hijos e hijas (El Obrero Municipal, 16-IX-1942). Probablemente refiriera a la ley 11.932 del año 1934, que permitía a las madres con hijos o hijas en edad de lactancia, dos descansos de media hora para el amamantamiento durante la jornada de trabajo (Biernat y Ramacciotti, 2011).

Por último, para nuestro sujeto de estudio, las enfermeras, existía un sistema que empeoraba las condiciones de trabajo: las suplencias. Ello consistía en ir a los lugares de trabajo con la esperanza que alguien

13 Una mirada de la militante socialista Josefina Marpons en la revista Mundo Argentino puede verse en Queirolo, 2016. 
se ausentara y así poder trabajar ese día. En teoría, si luego surgía alguna posibilidad de contratación en la planta permanente, las suplentes tenían prioridad. En no pocas ocasiones las enfermeras suplentes trabajaban gratis y solo recibían las propinas a la espera de obtener el trabajo a futuro (Horowitz, 2004: 74). El sindicato reparaba en ello en su pedido de mejoras: "el personal suplente de hospitales, más puestos para enfermeras y mucamas, mejor distribución de los puestos, denuncias sobre ingresos acomodados, etc." (El Obrero Municipal, 16-IX-1939). El tema de los acomodos, incluso, era señalado por los concejales en una serie de intervenciones propiciadas en el periódico gremial:

"ha existido la tendencia de ocupar niñas que necesitan un sueldo, no para colmar las necesidades de su hogar, sino para satisfacer caprichos femeninos. Si vemos en los hospitales a estas niñas a las cuales se les ha dado preferencia, que pertenecen a una clase especial, que llevan dos o tres apellidos, que llevan las uñas pintadas, que aseveran su clase, pensando internamente digo ¿cuándo estas niñas deben realizar tareas que por su situación no se hallan en condiciones de hacerlas con sus manos, quién debe hacerlo?"."

El tema de las suplencias de las enfermeras porteñas, además de ser recurrente como temática en la UOEM, conllevó la atención de varios concejales, como por ejemplo la de José Penelón, del partido Concentración Obrera, quien presentó un proyecto en el Concejo Deliberante para incorporar a dichas trabajadoras de la salud de modo permanente a la planta estatal de la comuna (Martin, 2014: 175).

\section{Reflexiones finales}

En los comienzos de la década de 1940, el PS podía mostrar un escenario dual respecto de su experiencia gremial. Por un lado, cuadros partidarios o dirigentes de filiación socialista conducían los más relevantes sindicatos del área de transportes y servicios y la principal central obrera. Por el otro, su peso era limitado en el sector industrial que por aquellos años se mostraba cada vez más dinámico. Pero, además, se evidenciaban una serie de problemáticas derivadas de su

14 Intervención del concejal Luis Boffi en El Obrero Municipal, 16-IX-1939. 
doctrina materializada en la "Declaración de Avellaneda", de 1918. Una de ellas era la aparente autonomización de las dirigencias sindicales respecto de las directivas partidarias. Observamos la defensa de parte de la dirección partidaria de la independencia de esferas entre lo político y lo gremial, su concepción evolutiva, la valoración de la acción política como superadora de la incierta práctica huelguística y, en definitiva, la exterioridad que proponía el Partido con relación al movimiento sindical. El contexto de los primeros años de la década de 1940 parecía invitar a una reconsideración que incluyera la modificación de los principios nodales y basales y, de este modo, reconfigurar la política socialista en el sindicalismo, hecho que finalmente sucederá de inmediato tras el golpe de Estado de 1943. Francisco Pérez Leirós, secretario general del sindicato municipal y figura visible que contrariaba dicha política de prescindencia dentro del PS, se expresaba al interior del sindicato, como vimos, en favor de dicha política de independencia y complementariedad de esferas entre el plano político y el gremial.

En el análisis del PS, el sindicato municipal y las enfermeras, de modo general, como vimos, muchas de las apelaciones del sindicato, volcadas en el periódico gremial, no escapaban de las clásicas nociones sobre virilidad y allí confluyeron con algunas imágenes volcadas en la prensa femenina del PS. Incluso esto era más nítido en el sindicato, la mujer era percibida en ocasiones como un obstáculo frente a la militancia masculina y el desarrollo normal y natural del rol de proveedor del varón. Otra de las demandas observadas, la igualdad salarial, estuvo impulsada en un contexto en el cual tanto el partido como el sindicato reproducían una práctica y una apelación permanente a la mujer desde su rol como madre. $Y$ ese maternalismo, a su vez, no solo reforzaba la naturalización de la función doméstica, sino que rearmaba de modo continuo la imagen sobre las dotes naturales con las que contaban las enfermeras de la ciudad de Buenos Aires. Así, este sector de la reproducción social era interpelado desde la existencia de ciertas características innatas. Como expresamos al inicio del artículo, esta mirada permite percibir la opresión de la mujer $-\mathrm{y}$, en este caso, de un sector específico de trabajadoras de la reproducción social como las enfermeras porteñas- como parte constitutiva, intrínseca al capitalismo, pues, aunque la primera preexiste a la segunda, adquiere bajo el capitalismo características específicas 
que al indagarlas habilitan capturar en profundidad dichas prácticas sociales (Bhattacharya, 2017).

Resulta evidente que, de modo global, tanto la UOEM como el PS obturaron una práctica que posibilitaba superar las demandas de mejoras del salario o de condiciones laborales, e inhibieron una interpelación de modo específico a las enfermeras. En paralelo, aunque de modo más específico y esporádico, las reivindicaciones ligadas a la jubilación femenina o el pedido del tiempo para el amamantamiento encontraron cierto espacio en la prensa gremial. De conjunto, la concepción maternalista tiñó las consideraciones del PS y del sindicato municipal acerca de las mujeres trabajadoras de la enfermería, apelando a ellas con tópicos propios del trabajo reproductivo, en ocasiones doméstico, y desde una concepción subsidiaria de la práctica masculina. Esta situación, claro está, no era excepcional en el movimiento obrero ni tampoco en el socialismo argentino (Becerra, 2009).

El trabajo encarado, entendemos, representa un aporte en tanto propone indagar la relación entre la estructura sindical y política con el sector de la enfermería. Allí, en el repaso del vínculo entre el PS, la Unión de Obreros y Empleados Municipales y las enfermeras porteñas, creemos recae la originalidad y contribución del estudio. Además, observar esta experiencia entre el partido, el sindicato y la fuerza de trabajo femenina de los hospitales porteños nos condujo a escrutar el modo de vinculación con uno de los sectores de la reproducción social.

\section{Referencias bibliográficas}

\section{Fuentes primarias}

\section{a) Publicaciones periódicas}

Acción Gremial, editado por la Comisión Socialista de Información Gremial, Buenos Aires, 1935.

Anuario Socialista, Buenos Aires, 1934-1943.

CGT, periódico de la Confederación General del Trabajo, Buenos Aires, 1937.

Comisión Socialista de Información Gremial, Buenos Aires, 1934.

Confederación General del Trabajo, Memoria y balance, 1937-1939, Buenos Aires, 1939. 
El Obrero Municipal, órgano de la Asociación Unión Obreros Municipales, Buenos Aires, 1930-1943.

La Vanguardia, Buenos Aires, 1930-1943.

Revista Socialista, Buenos Aires, 1933.

Vida Femenina, la revista de la mujer inteligente, Buenos Aires, 19301943.

\section{Fuentes secundarias}

a) Artículos y capítulos de libros

Barrancos, D. (2005). "Socialismo y sufragio femenino: Notas para su historia (1890-1947)", en C. Herrera y H. Camarero, (eds.). El Partido Socialista en Argentina: Sociedad, política $e$ ideas a través de un siglo. Buenos Aires: Prometeo, pp. 159184.

Biernat C. y K. Ramacciotti (2011). "La protección a la maternidad de las trabajadoras en Argentina”, en História, Ciências, SaúdeManguinhos, vol. 18, $\mathrm{N}^{\circ} 1$, pp. 153-177.

Biernat, C. y G. Queirolo (2018). "Mujeres, profesiones y procesos de profesionalización en la Argentina y Brasil", en Anuario del Instituto de Historia Argentina, vol. 18, $\mathrm{N}^{\circ} 1$.

Blanco, J. (2018). "Ser parte de. Los cuadros sindicales de la Federación Socialista de Córdoba en los años treinta", en Izquierdas, $\mathrm{N}^{\circ} 43$, pp. 79-101.

Camarero, H. (2011). "Del auge al declive: las corrientes de izquierda y los trabajadores antes del peronismo. Elementos para una interpretación teórica e historiográfica global", en Iberoamérica Global, N²2, pp. 49-79.

Camarero, H. (2015). "La CGT en disputa. Prescindencia apolítica de la dirección sindicalista y frentepopulismo comunista, 19351939", en Cuadernos del Ciesal, $\mathrm{N}^{\circ} 14$, pp. 35-58.

Ceruso, D. (2017a). "El Partido Socialista y la cuestión gremial. Debates internos durante la primera mitad de la década infame", en Archivos de historia del movimiento obrero y la izquierda, vol. 5, No10, p. 119-139.

Ceruso, D. (2017b). "El Partido Socialista y el movimiento sindical tras la conquista de la Confederación General del Trabajo (19351937)", en Páginas, revista digital de la Escuela de Historia, N²0, pp. 131-146. 
Ceruso, D. (2019a). “El Partido Socialista, la Confederación General del Trabajo y el debate por la prescindencia en los años finales de la 'década infame' en Argentina", en Revista Divergencia, $\mathrm{N}^{\circ} 12$, pp. 33-50.

García, L. (2017). “En torno al concepto de 'prescindencia': la corriente sindicalista al frente de la CGT (1930-1935)", en Archivos de historia del movimiento obrero y la izquierda, $\mathrm{N}^{\circ} 10$, pp. 95115.

Martínez Mazzola, R. (2011). "La neutralidad como problema y como solución. La política gremial del Partido Socialista después de la ruptura sindicalista", en Identidades, $\mathrm{N}^{\circ} 1$, pp. 2-20.

Poy, L. (2016). 'Neutralistas' y 'políticos'. Los debates en el Partido Socialista argentino acerca de la relación entre partido y sindicato, 1901-1904", en Avances del Cesor, $\mathrm{N}^{\circ} 15$, pp. 19-38.

Queirolo, G. (2016). “Dobles tareas: los análisis de Josefina Marpons sobre el trabajo femenino en la década de 1930", en Anuario de la Escuela de Historia Virtual, N9, pp. 81-97.

Rubinzal, M., V. Bolcatto y P. Sedran (2019). “Orígenes de la profesionalización de la enfermería y de las visitadoras de higiene en la ciudad de Santa Fe", en Trabajos y Comunicaciones, $\mathrm{N}^{\circ} 49$.

Valobra A. y K. Ramacciotti (2008). "Profesión, vocación y lealtad en la enfermería peronista", en C. Barry, K. Ramacciotti y A. Valobra, (eds.). La Fundación Eva Perón y las mujeres: entre la provocación y la inclusión. Buenos Aires: Biblos, pp. 119-150.

Valobra A. y K. Ramacciotti (2010). "La profesionalización de la enfermería en Argentina: disputas institucionales y políticas durante el peronismo", en Asclepio, vol. 62, N²2, pp. 353-374.

Varela. P. (2020). "La reproducción social en disputa: un debate entre autonomistas y marxistas", en Archivos de historia del movimiento obrero y la izquierda, $\mathrm{N}^{\circ} 16$, pp. 71-92.

Villalta, C. (2010). "La conformación de una matriz interpretativa La definición jurídica del abandono y la pérdida de la patria potestad", en L. Lionetti y D. Míguez, (comp.). Las Infancias en la Historia Argentina. Intersecciones entre Prácticas, Discursos e Instituciones (1880-1960). Buenos Aires: Prohistoria, pp. 71-93.

Wainerman, C. y G. Binstock (1992). "El nacimiento de una ocupación femenina: La enfermería de Buenos Aires", en Desarrollo Económico, $\mathrm{N}^{\circ} 126$, pp. 271-284. 


\section{b) Libros}

Aricó, J. (1999). La hipótesis de Justo. Escritos sobre el socialismo en América Latina. Buenos Aires: Sudamericana.

Barrancos, D. (1990). Anarquismo, educación y costumbres en la Argentina de principios de siglo. Buenos Aires: Contrapunto.

Becerra, M. (2009). Marxismo y feminismo en el primer socialismo argentino. Enrique Del Valle Iberlucea. Rosario: Prohistoria Ediciones.

Belkin, A. (2018). Sindicalismo revolucionario y movimiento obrero en la Argentina: de la gestación en el Partido Socialista a la conquista de la FORA (1900-1915). Buenos Aires: Imago Mundi/ Ediciones CEHTI.

Bhattacharya, T. (ed.). (2017). Social Reproductive Theory. Remapping Class, Recentering Oppression. Londres: Pluto Press.

Camarero, H. (2007). A la conquista de la clase obrera. Los comunistas y el mundo del trabajo en la Argentina, 1920-1935. Buenos Aires: Siglo XXI Editora Iberoamericana.

Ceruso, D. (2015). La izquierda en la fábrica. La militancia obrera industrial en el lugar de trabajo, 1916-1943. Colección Archivos. Buenos Aires: Imago Mundi.

del Campo, H. (2005). Sindicalismo y peronismo. Los comienzos de un vínculo perdurable. Buenos Aires: Siglo Veintiuno Editores.

Di Tella, T. (2003). Perón y los sindicatos. El inicio de una relación conflictiva. Buenos Aires: Ariel.

Dickmann, E. (1946). Socialismo y gremialismo. Buenos Aires: Pequeño Libro Socialista.

Haupt, G. (1986). El historiador y el movimiento social. Madrid: Siglo XXI.

Herrera, C. (2016). ¿Adiós Al Proletariado? El Partido Socialista bajo el peronismo (1945-1955). Buenos Aires: Imago Mundi.

Herrera, C. (2019). En vísperas del diluvio: el gremialismo socialista ante la irrupción del peronismo. Colección La Argentina Peronista. Mar del Plata: EUDEM.

Horowitz, J. (2004). Los sindicatos, el Estado y el surgimiento de Perón, 1930-1946. Buenos Aires: Eduntref.

López, A. (1935). Valor del sindicato obrero. Buenos Aires: Pequeño Libro Socialista. 
Matsushita, H. (1986). Movimiento Obrero Argentino, 1930-1945: Sus proyecciones en los orígenes del peronismo. Buenos Aires: Hyspamérica.

Nari, M. (2004). Políticas de Maternidad y Maternalismo Político. Buenos Aires, 1890-1940. Buenos Aires: Biblos.

Oddone, J. (1983). Historia del socialismo argentino, 2 tomos. Buenos Aires: CEAL.

Poy, L. (2014). Los orígenes de la clase obrera argentina. Huelgas, sociedades de resistencia y militancia política en Buenos Aires (1888-1896). Buenos Aires: Imago Mundi.

Tortti, M. (1989). Clase obrera, partido y sindicatos: estrategia socialista en los años '30. Serie Cuadernos de Historia Argentina ( $\left.\mathrm{N}^{\circ} 2\right)$. Buenos Aires: Biblos.

Vogel, L. (2013). Marxism and the Oppression of Women. Toward a Unitary Theory. London: Historical Materialism-Brill.

Wainerman, C. y G. Binstock (1993). Ocupación y género. Mujeres y varones en enfermería. Buenos Aires: Cuadernos del C.E.N.E.P.

c) Tesis

Martin, A. (2014). Parir, cuidar y asistir. El trabajo de las parteras y enfermeras en Buenos Aires (1877-1955). Tesis para optar el grado académico de Doctora en Historia. Buenos Aires: Universidad de Buenos Aires.

d) Otros

Ceruso, D. (2019b). "El vínculo entre las izquierdas y el movimiento obrero. Un análisis de la experiencia del Partido Socialista argentino en los últimos años de la década de 1930", en Nuevo Mundo Mundos Nuevos, http://journals.openedition.org/ nuevomundo/75901, revisado el 3-II-2020.

Ramacciotti, K. I. (coord. de dossier). (2019). “La profesionalización del cuidado sanitario. La enfermería en la historia argentina", en Trabajos y Comunicaciones, $\mathrm{N}^{\circ} 49$, https://www.trabajosycomunicaciones.fahce.unlp.edu.ar/issue/view/436, revisado el 21-I-2020.

Tortti, M. (s/f). "El Partido Socialista ante la crisis de los años 30' La estrategia de la 'revolución constructiva", en http://www. historiapolitica.com/datos/biblioteca/tortti3.pdf, revisado el 13-XII-2019. 